\title{
ИНСТИТУЦИОНАЛЬНЫЕ ИЗМЕНЕНИЯ И ЦИФРОВАЯ ЭКОНОМИКА
}

\author{
(c) 2019 Трубецкая Ольга Вениаминовна \\ кандидат экономических наук, доцент \\ Самарский государственный экономический университет, Россия, Самара \\ e-mail: olgatrub@gmail.com
}

Актуальность исследуемой проблемы обусловлена тем, что теория институциональных изменений слабо раскрыта в российской экономической мысли, в то время как институциональная система формирует предпосылки экономического роста и развития, а также обеспечивает условия необходимые для перехода к цифровой экономике. В статье выявляются подходы к теории институциональных изменений, особенности трактовки категории «цифровая экономика», проводится количественная оценка институциональных изменений за период 2010-2017 гг. по таким параметрам, как плотность институциональной среды, вектор институциональных изменений, групповая структура и параметры трансакционных издержек.

Ключевые слова: институциональная система, институт, институциональные изменения, циффровая экономика, цифровые технологии, цифровое развитие, векторы институциональных изменений, трансакционные издержки.

В современных условиях основным детерминирующим фактором институциональных изменений в экономике, по мнению авторов, выступает её цифровизация. Анализируя основные подходы к пониманию сущности цифровой экономики, авторы обосновывают необходимость существенных институциональных изменений, без которых невозможен успешный переход к цифровой модели экономического развития.

Целью исследования является количественная оценка динамики институциональных изменений на основе анализа законодательной практики современной России, характеризующая вектор институциональных изменений, а также оценка готовности перехода России к цифровой экономике. В процессе исследования использовались методы: теоретические (анализ, синтез, обобщение, метод аналогии), что позволило выявить характеристики институциональных изменений, которые поддаются количественной оценке. Оценка плотности институциональной среды, вектора институционального развития стала возможной благодаря использованию метода эмпирического сравнения. Методы математической статистики позволили сформировать группы статистических данных, с помощью которых проведена оценка количественных параметров модели институциональных изменений.

Под процессом институциональных изменений мы будем понимать изменение формаль- ных и неформальных правил, норм и принуждений, составляющих институциональную среду общества.

В России точкой отсчета по развитию цифровой экономики можно считать Послание Президента РФ Федеральному собранию от 01.12.2016 г., в котором было поручение предложить системные подходы к наращиванию кадровых, интеллектуальных, технологических возможностей РФ в области цифровой экономики. Программа «Цифровая экономика», разработанная Экспертным советом при Правительстве РФ предполагает выполнение ряда целей: рост включенности граждан и хозяйствующих субъектов в работу в цифровом пространстве, создание инфраструктуры, обеспечивающей взаимодействие субъектов в цифровом пространстве, снижение издержек хозяйствующих субъектов и граждан при взаимодействии с государством и между собой, повышение конкурентоспособности экономики.

При этом внедрение сквозных цифровых технологий, как большие данные, нейротехнологии и искусственный интеллект, блокчейн, квантовые технологии, промышленный интернет, компоненты робототехники и сенсорика, технологии беспроводной связи, потребует изменения в формальных и неформальных правилах, нормах и принуждениях, что представляет собой институциональные изменения.

Норт Д., рассматривая причины изменений 
институтов, делал вывод о том, что институциональные изменения происходят потому, что для экономических агентов или групп становится выгодным пойти на определенные издержки для осуществления этих изменений, так как они позволят индивидам получить дополнительную прибыль [7].

Элснер В. связывает теорию институциональных изменений с теорией игр в ее эволюционноинституциональной интерпретации, что позволяет проводить более углубленный анализ институтов, выявляя ценностную базу в теории игр, инструментально-церемониальную асимметрию [1].

Для российской науки проблематика институциональных изменений является сравнительно новой. Однако уже сегодня можно отметить существенный вклад, который внесли в изучение теории изменений институтов В. Тамбовцев, В. Вольчик, А. Шаститко, С. Кирдина и др. В их исследованиях представлены характеристики институтов, институциональной среды, теории и методологии анализа, особенности институциональных изменений в российской экономике, а также региональный аспект институционального развития [2, 3].

Мещеряков P. рассматривает цифровую экономику с двух позиций: во-первых, это экономика, основанная на развитии цифровых технологий, в первую очередь область услуг и электронных товаров. Во-вторых, цифровую экономику можно исследовать как экономическое производство с использованием цифровых технологий [4]. Юдина Т. считает цифровую экономику новой социо-культурно-экономической реальностью в новом мире, «умной» действительностью [5].

Но ключевым фактором во всех определениях является обмен знаниями, технологиями посредством людей, способных участвовать в этом обмене и управлять им.

По оценкам специалистов, Россия заметно продвинулась по многим направлениям цифрового развития. Произошло увеличение внутренних затрат на исследования и разработки в организациях информационно-компьютерных технологий (ИКТ) с 1,3\% до 3,6\% в 2016 г., возросло количество абонентов широкополосного доступа к интернет - с 12,2\% в 2011 г. до 21\% в 2017 г. Также возрос удельный вес организаций, использующих интернет с 56,7\% в 2010 г. до 81,8\% в 2017 г., доля организаций, размещаю- щих заказы в интернете, увеличилась за рассматриваемый период на 6,6\%, а доля организаций, получающей заказы на выпускаемые товары по сети возросла на 2,4\% [6].

Вместе с тем, доля валовой добавленной стоимости сектора к ВВП сократилась с 3,4\% в 2010 г. до 2,9\% в 2016 г. и она в 2-3 раза меньше, чем в станах лидерах, что говорит об отставании в развитии цифрового сектора российской экономики. Дальнейшее развитие цифровой экономики потребует трансформацию формальных и неформальных правил и ограничений, системы стимулов для экономических агентов, то есть институциональных изменений.

Для оценки существующих и происходящих институциональных изменений в российской экономике авторы статьи взяли базу Lawstream. $\mathrm{ru}$, в которой содержатся данные о федеральных законах, сформированных путем синтеза данных с официального сайта Государственной Думы ФС РФ и информации, представленной в справочной правовой системы Консультант Плюс. Данную базу авторы дополнили расчетами за 2017 г, а также отдельно был выделен сектор информационно-коммуникационных технологий, включающий в себя данные, связанные с информацией, информационно средой, коммуникацией, и обеспечением информационной безопасности юридических и физических лиц для оценки готовности институционной среды к цифровой экономике.

Для оценки институциональных изменений используются такие характеристики институциональной среды, как плотность, показателем которой выступает количество необходимых законов и их структура, а также оценки роли основных групп законодательного процесса в осуществлении институциональных изменений и оценка динамики трансакционных издержек в процессе принятие федеральных законов. Для того, чтобы оценить плотность институциональной среды, рассмотрим данные о количестве законов, их структуре и сферах регулирования на рис. 1.

Можно видеть, что максимальное количество принятых законов было в 2014 г., в дальнейшем происходит выравнивание уровня принятых законов до ситуации 2011г, а в 2017 г. наблюдается резкий спад. При этом пики и минимумы принятия федеральных законов соотносятся со сроками начала или окончания полномочий депутатов Государственной Думы ФС 


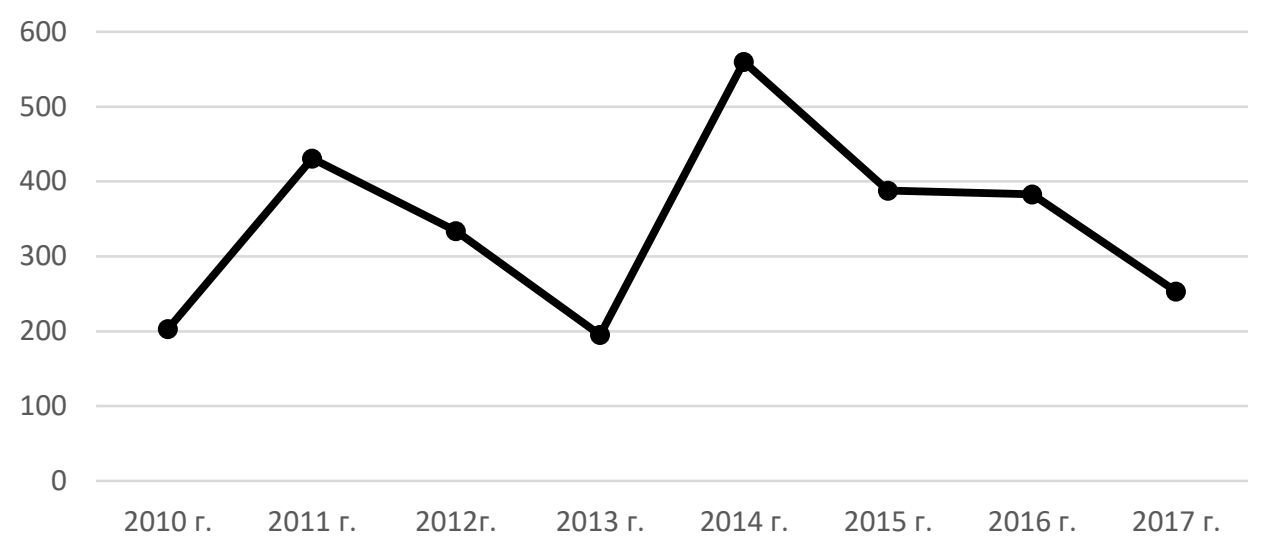

Puc. 1. Количество принятых законов за 2010-2017 гг.

(Рассчитано автором на основе www.duma.gov.ru; https://consultant.ru)

РФ. Так, пик принятия федеральных законов 2011 года пришелся на окончание работы думы 5 созыва, а спад 2016-2017 гг. связан с началом работы думы 7 созыва.

Рост законодательной активности депутатов к концу срока полномочий может быть связан с их стремлением доделать то, что накопилось за годы парламентской деятельности, так как приход новых парламентариев может усложнить или вообще прекратить работу в сфере продвижения конкретной законодательной инициативы. Тенденции в области федерального законодательства позволяют судить о росте плотности институциональной среды, в которой законы играют значительную роль.

Распределение принятых федеральных законов по сферам регулирования (см. табл. 1) показывает, что большая часть законов принималась в сферах экономики и финансов (в среднем 21,2\%), кодексов $(24,1 \%)$ и иных законов (в среднем 38,6\%). В сфере информационно-компьютерных технологий количество принятых законов было минимальным (в среднем 0,65\%), что говорит о низкой плотности институциональной среды в сфере информационных технологий, а также о том, что рост цифрового сектора не совпадает с изменениями в соответствующих институтах.

О векторе институциональных изменений позволяет судить не только динамика плотности институциональной среды, но также соотношение новых законов и законов, вносящих поправки в действующие законы. Если в 2010 г. доля новых законов в сфере «Экономика и финансы» достигала 19,7\%, в сфере «Политика и государственное устройство - 23,3\%, «Иные законы» - 55,6\%, то в 2017 г. их доля снизилась соответственно до $12,5 \%$ в сфере экономики, до 9,5\% в сфере «иные законы», до 8\% в сфере политики и государственного устройства. Особенность принятия новых законов в информационном секторе заключается в том, что новые законы были приняты только в 2013 и 2017 г.

Можно выделить несколько очевидных тенденций. Во-первых, долговременный процесс

Таблица 1. Распределение принятых федеральных законов по сферам регулирования (в \% по дате внесения)

\begin{tabular}{|c|c|c|c|c|c|}
\hline Годы & $\begin{array}{c}\text { Экономика } \\
\text { и финансы }\end{array}$ & $\begin{array}{c}\text { Политика и } \\
\text { государственное } \\
\text { устройство }\end{array}$ & Кодексы & ИкТ & Иные законы \\
\hline 2010 & 31 & 19,7 & 14,4 & 0,2 & 34,7 \\
\hline 2011 & 23,8 & 15,2 & 16,3 & 0,1 & 44,7 \\
\hline 2012 & 20,9 & 16,1 & 20 & 0,1 & 43 \\
\hline 2013 & 22,2 & 15,3 & 20,2 & 0,1 & 42,2 \\
\hline 2014 & 9,8 & 15,8 & 25,6 & 1,5 & 52,1 \\
\hline 2015 & 13,3 & 14 & 20,4 & 0,2 & 38,5 \\
\hline 2016 & 26,5 & 18 & 17 & 1 & 6,5 \\
\hline 2017 & 22,1 & 9,8 & 59,6 & 2 & 38,6 \\
\hline В среднем & 21,2 & 15,5 & 24,1 & 0,65 & \\
\hline
\end{tabular}


сокращения доли новых законов в общем числе принятых за эти годы федеральных законов характерен для всех сфер регулирования. Во-вторых, можно выделить сферы, где коррекция законодательства происходит чаще, чем в других. Как следует из предоставленных данных, кодексы гораздо чаще подвергаются уточнению, чем другие федеральные законы. Это видно по наименьшей доле новых законов в сфере принятия кодексов (доминируют поправки).

В целом можно сделать вывод о некоторой стабилизации институциональной среды, поскольку основное внимание чаще направляется на совершенствование законодательства, чем на принятие новых законодательных форм. С другой стороны, высокая доля поправок может характеризовать тот факт, что законы принимаются недостаточно продуманно и приходится их постоянно подправлять.

Что касается цифровой сферы, то низкая доля принятия новых законов в общем незначительном количестве принятых законов в этой области говорит скорее о неразвитости институциональной среды.

Оценить трансакционные издержки институциональных изменений можно, рассмотрев время принятия законов в зависимости от года внесения закона («длина очереди»), в зависимости от года принятия закона («скорость рассмотрения»).

Количество дней, которое затрачено законодателями в процессе принятия закона представляет собой трансакционные затраты согласования субъектов законотворчества.

Средний срок прохождения закона составил в 2011 г. 251 день, а в 2017 г. он сократился до 212 дней.

Наиболее существенное снижение отмечается в отношении законов, внесенных президентом - всего 74 дня дожидались утверждения законопроекты, внесенные президентом в
Государственную Думу в 2017 г. Законопроекты правительства и судов ждали своего утверждения в этом году в среднем 160 и 178 дней соответственно. Для законов, инициированных региональными субъектами, а также депутатами федерального собрания, срок ожидания составил 260 и 210 дней, что выше, чем у остальных субъектов.

Рассматривая динамику за весь период, можно выявить общие тенденции по сокращению сроков прохождения для всех законопроектов, независимо от инициатора, но темпы ее сокращения различались. Если для президентских законопроектов сроки рассмотрения сократились в 2 раза, то для законов региональных субъектов сокращение составило незначительную величинy.

Таким образом, на основании полученных результатов, можно сделать вывод об увеличении плотности институциональной среды. При этом реформирование институциональной среды носит неоднородный характер: большинство принятых законов относится к экономической сфере и сфере кодексов. В цифровом секторе количество принятых законов минимально, что говорит о низкой плотности институциональной среды, а также о том, что формальные изменения не успевают за неформальными трансформациями норм и правил.

Общий вектор институциональных изменений говорит о росте стабильности институциональной среды, что выражается в снижении доли новых законов по сравнению с принятием поправок в уже существующее федеральное законодательство Можно выделить сферы, где коррекция законодательства происходит чаще: это кодексы. В разрезе с основными тенденциями находится сектор ИКТ, здесь наблюдается увеличение доли новых законов, что говорит скорее о неразвитости институтов в этой области.

\section{Библиографический список}

1. Элснер В. Снова об институционалисткой теории институциональных изменений: институциональная дихотомия в более формальном представлении// Journal of Institutional studies. 2017.Том 9 № 2, 6-17

2. Кирдина С.Г., Кирилюк И.Л., Толмачева И.В., Рубинштейн А.А. Российская модель институциональных изменений: опыт эмпирико-статистического исследования// Вопросы экономики.2010. № 11, 97-114.

3. Вольчик В. Эволюционный подход к анализу институциональных изменений//TERRA Economicus. 2012.ToM 10, № 4. 62-69

4. Мещеряков Р., Савчук М.. Подходы к внедрению ERP-систем на крупных предприятиях// Бизнес информатика. 2011. № 2(16). 63-67 
5. Юдина Т. Н., Тушканов И.М. Цифровая экономика как результат промышленно-технологической революции (теоретические и практические аспекты). URL: http://reosh.ru/t-n-yudina-i-m-tushkanov-cifrovayaeconomika-kak-resuktat-proyshlenno-texnologicheskoj-revolyucii-teoreticheskie-i-prakticheskie-aspekti.htm

6. Индикаторы цифровой экономики. Статистический сборник. Нац. исслед. ун-т «Высшая школа экономики». 2017.

7. North D.C., Thomas R.P. An Economic Theory of the Growth of the Western World// Economic History Review. 1970. Vol. 23. № 1, 1-17 